\title{
Mengukur Kesiapan Elektronik Dalam Mewujudkan Pariwisata Cerdas : Studi Kasus Kota Malang
}

\author{
Tatang Satya Wibowo $^{1 *}$, Endroyono ${ }^{1}$ dan Istas Pratomo ${ }^{1}$ \\ ${ }^{1}$ Departmen Teknik Elektro, Institut Teknologi Sepuluh Nopember, Surabaya \\ *Corresponding Author \\ E-mail: tatang.17071@mhs.its.ac.id
}

\begin{abstract}
Abstrak
Pariwisata ditetapkan sebagai sektor yang penting untuk dikembangkan dan dibina sebagai sektor unggulan. Untuk memperoleh informasi tentang pariwisata dengan memanfaatkan TIK disebut pariwisata cerdas. Agar pengembangan pariwisata cerdas dapat di implementasikan, perlu adanya persiapan elektronik. Pengukuran kesiapan Infrastruktur TIK ini diharapkan sebagai tool dalam memaksimalkan potensi pariwisata di Kota Malang. Metode penelitian ini dimulai dengan menentukan dimensi kesiapan yaitu menggunakan New e-readiness integrated model, yang terdiri dari 5 dimensi kesiapan. Setelah disusun pernyataan, dilakukan survey interen untuk mengetahui apakah pernyataan tersebut valid atau tidak. Setelah hasilnya valid maka baru dilaksanakan survei tehadap Organisasi Perangkat Daerah (OPD) Pemerintah Kota Malang dan juga wisatawan. Kemudian dilakukan uji validitas dan uji reliabilitas. Kesimpulan dari penelitian ini adalah Pemerintah Kota Malang siap dalam mewujudkan Pariwisata Cerdas.
\end{abstract}

Kata Kunci: Pariwisata Cerdas, e-readiness, uji validitas, uji reabilitas.

\begin{abstract}
Tourism is determined as an important sector to be developed and fostered as a leading sector. To obtain information about tourism by utilizing ICTs is called smart tourism. For intelligent tourism development to be implemented, electronic preparations are needed. Measurement of ICT Infrastructure readiness is expected to be a tool in maximizing tourism potential in Malang. This research method begins by determining the dimension of readiness by using the New e-readiness integrated model, which consists of 5 dimensions of readiness. After compiling the statement, an internal survey is conducted to find out whether the statement is valid or not. After the results are valid, a survey of the Regional Government Organizations (OPD) of Malang City Government and tourists is also carried out. Then do the validity test and reliability test. The conclusion of this research is the Government of Malang City is ready to realize Smart Tourism.
\end{abstract}

Keywords: Smart Tourism, e-readiness, validity test, reliability test.

\section{PENDAHULUAN}

Pada tahun 2017 Presiden Joko Widodo menetapkan 10 tujuan wisata Bali Baru yaitu Danau Toba (Sumatera Utara), Tanjung Kelayang (Belitung), Tanjung Lesung (Banten), Kota Tua dan Kepulauan Seribu (DKI Jakarta), Borobudur (Jawa Tengah), Bromo Tengger Semeru (Jawa Timur), Mandalika (Nusa Tenggara Barat), Labuan Bajo (Nusa Tenggara Timur), Wakatobi (Sulawesi Tenggara), dan Morotai (Maluku Utara). Secara geografis, Kota Malang diuntungkan dengan penetapan kawasan Bromo Tengger Semeru. Hal tersebut disebabkan walaupun Kota 
Malang tidak mempunyai wisata alam, tetapi merupakan jalus distribusi yang akan berkunjung ke Kawasan Bromo tengger Semeru, Kabupaten Malang dan Kota Batu.

Ditengah ketatnya persaingan pada industri pariwisata dengan potensi sumber daya alam yang semakin terbatas, maka pemerintah daerah setempat dan stakeholder harus mampu menciptakan atau mengembangkan potensi pariwisata di daerah. Kota Malang dikenal sebagai kota pendidikan dan kota wisata, untuk itu perlu dilakukan analisis kesiapan kota malang dalam mewujudkan pariwisata cerdas.

Pariwisata kini menjadi sektor unggulan di dunia. Seperti di bidang lain, penggunaan tema pariwisata cerdas tidak lepas dari integrasi teknologi informasi dan komunikasi (TIK). Pemanfaatan teknologi sensor, big data, open data, Internet of Things (IoT), dan sebagainya. Beberapa Obyek wisata dan fasilitas pariwisata belum memanfaatkan kemajuan teknologi yang berkembang saat ini. Penelitian ini bertujuan untuk mengetahui Analisis Kesiapan Kota Malang Dalam Mewujudkan Pariwisata Cerdas. Kota-kota dengan inovasi dan perkembangan teknologi dalam kehidupan kotanya ini sering disebut sebagai Kota Cerdas (Smart City). Untuk itu diusulkan framework untuk menilai sehingga dapat mengurangi kesulitan terkait dengan pengembangan yang tidak efektif.

\section{METODOLOGI}

\subsection{Kajian Penelitian Terkait}

Kajian penelitian terkait adalah perbandingan berbagai alat penilaian e-readiness Integrasi digital, penerapan infrastruktur Teknologi Informasi (TI) dari e-government, e-commerce, elearning, dan aplikasi-aplikasi elektronik lainnya, menjadi milik semakin penting untuk pembangunan secara nasional dan internasional (Ghavamifar,A, Beig,L, Montazer,G.A, 2008).[1]

A Selection Framework of E-Business Model by Assessing Organizational E-Readines (K. Mohitmafi, P. Hanafizadeh, 2016) yang membahas metode pengambilan keputusan yang dapat membantu organisasi untuk memilih model bisnis yang sesuai ebusiness model (EBM) berdasarkan pada "organizational e-readiness assessment" (OERA). [2]

Understanding Travelers' Behavior for Sustainable Smart Tourism: A Technology Readiness Perspective (Pradhan,M.K., Oh, J and Lee, H,. 2018), Penelitian ini membahas pariwisata cerdas telah berkontribusi untuk membuat perjalanan orang lebih mudah dan lebih menyenangkan, tetapi terkadang memiliki dampak negatif pada pengalaman perjalanan mereka (dampak optimisme, inovasi, rasa tidak aman, dan ketidaknyamanan). [3] Penelitian ini menyelidiki persepsi risiko wisatawan tentang pariwisata cerdas dari perspektif kesiapan teknologi. Hasil penelitian menunjukkan bahwa manfaat yang dirasakan dari perangkat pintar memiliki pengaruh signifikan terhadap niat penggunaan perangkat cerdas ketika dalam perjalanan.

\subsection{E-readiness}

E-readiness adalah salah satu indikator utama pembangunan suatu daerah. Hal tersebut digunakan untuk mengambil atau menentukan keputusan atau mengidentifikasi variabel penting yang mempunyai pengaruh berdasarkan data data yang ada. Sejak kemunculan TIK, perkembangan ekonomi baru lebih di titik beratkan untuk memajukan pertumbuhan ekonomi dan produktivitas. Oleh karena itu e-readiness sangat terkait dengan kinerja ekonomi nasional, sumber daya manusia dan tata kelola di negara-negara berkembang (Grigorovici, 2004). Pemerintah 
mempunyai peran penting dalam penyediaan layanan TIK dan mendorong penggunaan teknologi digital oleh masyarakat.

Penilaian e-readiness adalah salah satu bagian penting dalam mengembangkan dan membangun sistem e-government dengan terus menilai variabel perubahan yang dicapai melalui beberapa alat penilaian e-readiness.

\subsection{E-Readiness Assessment Tools.}

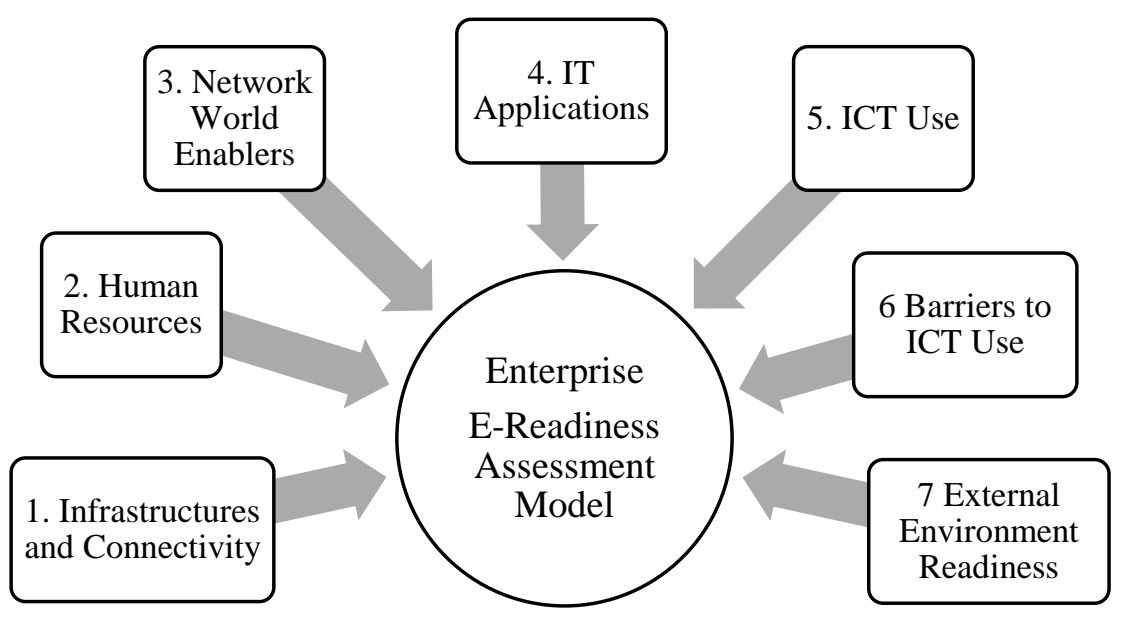

Gambar 1. Dimensi indikator OERA

Penggunaan alat pengukuran pada indikator diatas menguraikan indikator umum yang didalamnya terdiri dari indicator yang lebih spesifik. Indikator-indikator ini menggambarkan ketersediaan suatu fitur dan tingkat ketersediaan beberapa fitur lain yang diperlukan untuk memberikan informasi tentang seberapa kesiapan suatu daerah atau komunitas untuk menerapkan dan menggunakan teknologi. Dimensi tersebut diambil beberapa yang terkait indikator OERA dan dikembangkan untuk menilai tingkat kesiapan di setiap dimensi. Komponen komponen dalam model tersebut akan digunakan sebagai indikator untuk menilai kesiapan dengan menyesuaikan kondisi yang ada di Kota Malang.

\subsection{Pariwisata Cerdas}

Werthner and Klein 1999; Benckendorf et al. 2014 menyatakan bahwa Smart Tourism adalah suatu cara untuk memperoleh informasi tentang tourism (pariwisata) dengan memanfaatkan ICT. Sebuah kota perlu mengembangkan pariwisata cerdas, salah satunya untuk menciptakan wisata yang inovatif yang dibangun di atas infrastruktur teknologi. Selain itu dengan pengembangan pariwisata cerdas dapat memudahkan wisatawan dan meningkatkan kualitas pengalaman berwisata di tempat tujuan wisata. Dengan tercapainya tujuan diatas, maka diharapkan dapat meningkatkan kualitas hidup warganya.

Sebuah kota dikatakan cerdas apabila memenuhi dipenuhi indikator berikut :

1. Meningkatnya kenyamanan wisatawan baik domestik maupun mancanegara,

2. Sesuai dengan personalized demand wisatawan,

3. Munculnya common sharing,

4. Penggunaan berbagai resource tourism \& culture secara efektif dan intensif. 
5. Adanya peran dan dukungan dari masyarakat

\section{HASIL DAN PEMBAHASAN}

Tahapan dalam penelitian ini terbagi dalam lima tahap, yaitu penyusunan indikator, pra proses pengumpulan data, pengumpulan data (survey), uji validitas dan uji reliabilitas, analisis kesiapan (e-readiness). Sebelum menyusun indikator dilakukan studi literatur pada penelitian sebelumnya. Setelah itu dibuat skala prioritas indikator mana yang paling banyak dipakai untuk digunakan sebagai indicator dalam membuat kuisioner. Penyusunan Tahapan - ahapan tersebut digambarkan pada diagram alir dibawah ini:

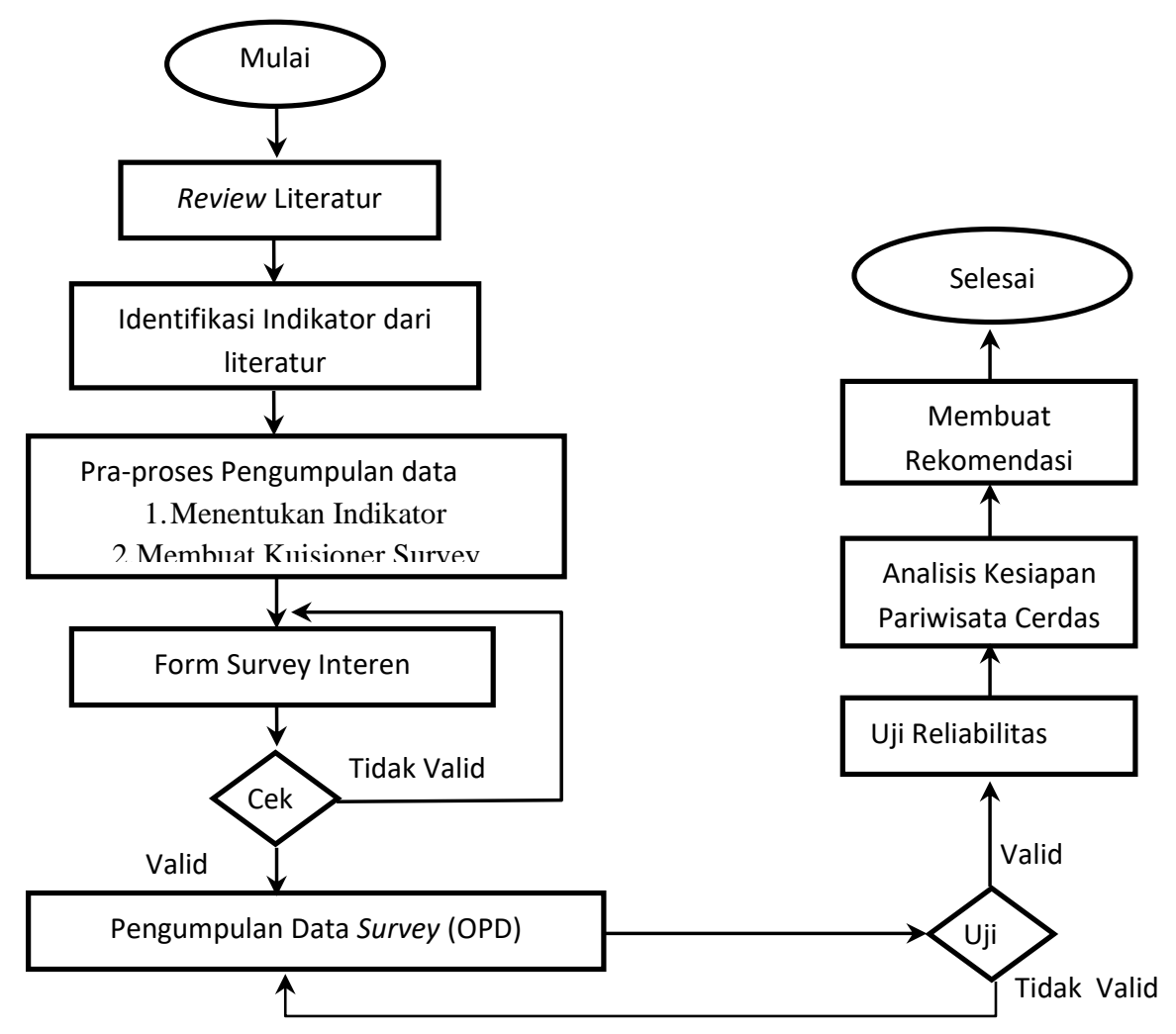

Gambar 2. Tahapan penelitian

\subsection{Persiapan Pengumpulan Data}

Dimensi untuk menilai tingkat kesiapan di setiap dimensi. Langkah persiapan pengumpulan data adalah mengidentifikasi indikator OERA dan mengalokasikannya ke dimensi kerangka kerja. Infrastructures and Connectivity, Human Resources, Network World Enablers, IT Applications, ICT Use, Barriers to ICT Use, dan External Environment Readiness. Dengan mengelompokan 7 dimensi kesiapan menjadi 5 dimensi kesiapan, kerangka kerja yang diusulkan dibagi lagi menjadi: 

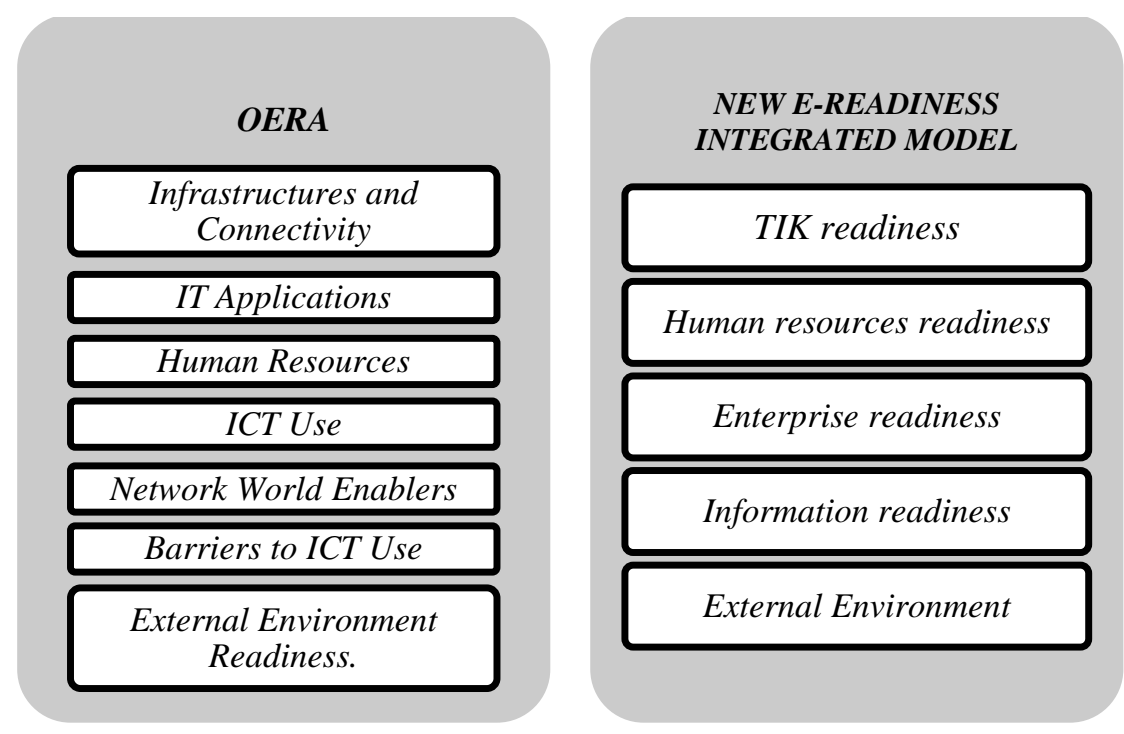

Gambar 3. Pengelompokan dimensi kesiapan

New e-readiness integrated model menekankan pada akses informasi dan juga segemen terkait, yaitu organisasi, ICT, sumber daya manusia, dan dukungan lingkungan eksternal ke dalam satu model penilaian kesiapan terpadu. Segmen kesiapan beserta jumlah komponen penilaian mengacu pada model Mutula dan Brakel (2006).

Setelah mengevaluasi ICT Readiness Assessment Model, maka dibentuk instrument penelitian. Pada penelitian ini instrument yang digunakan yaitu kuesioner dan daftar pertanyaan wawancara. Setelah instrument dibuat, dilakukan survey interen untuk menguji validasi atas kuesioner tersebut. Setelah pernyataan dinyatakan valid marulah dilaksanakan survey yang sebenarnya. Metode pengumpulan data terdiri dari data primer yang diambil secara langsung (wawancara dan orservasi lapangan) dan data sekunder yang diperoleh dengan menggunakan data data referensi terkait. Dalam pengambilan data penelitian, menggunakan dengan metode accidental sampling.

Penelitian dilaksanakan dengan melibatkan Organisasi Perangkat Daerah (OPD), wisatawan dan pelaku usaha pariwisata agar bisa memetakan indikator dan memperoleh data yang diharapkan dan terperinci dari berbagai sumber. Pengambilan data survey dilakukan pada Kepala Dinas, Sekretaris, Kepala Bidang, Kepala Seksi, atau staf / bagian yang membidangi TIK.

\subsection{Pengujian Validitas}

Untuk mengetahui sebuah instrument yang akan diukur dikatakan valid memerlukan Uji validitas. Dalam penelitian ini menggunakan produk pearson korelasi momen. Jika nilai $\mathrm{r}_{\mathrm{xy}}$ lebih besar daripada $\mathrm{r}_{\text {table }}\left(\mathrm{r}_{\mathrm{xy}}>\mathrm{r}_{\text {table }}\right)$ maka instrument tersebut dikatakan valid. $\mathrm{R}$ tabel adalah sebuah tabel angka yang biasa digunakan untuk menguji hasil uji validitas suatu instrumen penelitian. Untuk mencari nilai $r$ tabel, dapat dilakukan dengan menggunakan rumus : ( $\mathrm{df}=\mathrm{n}-2$ ). Pernyataan kuesioner diumumkan valid jika $r_{x y}>0,373$, sedangkan $r_{x y}$ tidak valid $<0,373$. Untuk mendapatkan nilai $r_{\mathrm{xy}}$ menggunakan rumus berikut:

$$
r_{\mathrm{xy}}=\frac{n\left(\sum x y\right)-\left(\sum x\right)\left(\sum y\right)}{\sqrt{\left\{n \sum x^{2}-\left(\sum x\right)^{2}\right\}\left\{n \sum y^{2}-\left(\sum y\right)^{2}\right)}}
$$


Dimana:

$\mathrm{r}_{\mathrm{xy}}=$ Koefisien korelasi antara $\mathrm{x}$ dan $\mathrm{y}$

$\mathrm{n} \quad=$ Jumlah responden

$\Sigma_{\mathrm{xy}}=$ Total data xy

$\Sigma_{\mathrm{x}} \quad=$ Jumlah total data variabel $\mathrm{x}$

$\Sigma_{\mathrm{y}}=$ Jumlah total data variabel y

Pengujian reliabilitas menggunakan cronbach's alpha $(\alpha)$ dengan koefisien alpha $(\alpha)$ cronbach lebih besar dari 0,6 ( $\alpha>0,6)$. Maka dapat disimpulkan bahwa pernyataan kuesioner dapat diterima, sedangkan jika koefisien alpha $(\alpha)$ cronbach lebih kecil dari 0,6 $(\alpha<0,6)$ maka pernyataan tersebut tidak dapat diterima. Untuk mendapatkan nilai koefisien $(\alpha)$ gunakan rumus berikut:

$$
\propto=\frac{k}{k-1} x\left(1-\frac{\sum s_{i}^{2}}{s_{t}^{2}}\right)
$$

Dimana:

$\propto \quad=$ koefisien reliabilitas

$k \quad=$ jumlah item yang valid

$s_{i}^{2} \quad=$ varian skor total

$s_{t}^{2} \quad=$ varian skor item

\subsection{Pengukuran kesiapan TIK dan kriteria skor}

Setiap pernyataan dalam kuesioner memiliki bobot penilaian dalam skala 1-5. Nilai 1 (satu) berarti Tidak Setuju, nilai 2 (dua) berarti kurang setuju, Nilai 3 berarti netral, Nilai 4 berarti setuju dan nilai 5 berarti sangat setuju. Skala yang digunakan dalam lima dimensi kesiapan tersebut, adalah : apabila nilai dari dimensi adalah 0 - 1,99 maka dikategorikan sangat tidak siap; dimensi dengan skala 2 - 2,99 dikategorikan tidak siap; dimensi dengan skala 3 - 3,99 dikategorikan cukup siap; dimensi dengan skala 4 - 4,99 dikategorikan siap dan dimensi dengan skala 5 dikategorikan sangat siap.

\section{HASIL DAN PEMBAHASAN}

Dalam penelitian ini menggunakan dua kuesioner yang didistribusikan ke OPD di lingkungan Pemerintah Kota Malang dan wisatawan yang berkunjung ke Kota Malang.

\subsection{Hasil uji validasi dan uji reliabilitas}

Hasil dari uji validasi menggunakan korelasi pearson product moment dapat dilihat pada tabel berikut:

Tabel 1. Hasil Uji Validasi

\begin{tabular}{|l|c|c|c|}
\hline & \multirow{2}{*}{$\begin{array}{c}\text { Jumlah } \\
\text { Subdomain }\end{array}$} & \multicolumn{2}{|c|}{ Jumlah Pernyataan } \\
\cline { 3 - 4 } & Pernyataan & Valid & Tidak Valid \\
\hline Pernyataan untuk OPD & & & \\
\hline 1.Enterprise readiness & 17 & 15 & 2 \\
\hline 2.Human resources readiness & 19 & 17 & 2 \\
\hline 3.Information readiness & 18 & 18 & 0 \\
\hline 4.TIK readiness & 20 & 20 & 0 \\
\hline 5.External Environment & 8 & 8 & 0 \\
\hline Pernyataan untuk wisatawan & 16 & 16 & 0 \\
\hline
\end{tabular}


Berdasarkan Tabel diatas, dapat diketahui jumlah pernyataan kuesioner yang dinyatakan valid dan tidak valid. Hasil uji validitas dari Enterprise readiness 15 dari 17 pernyataan dinyatakan valid, Human resources 17 dari 19 pernyataan dinyatakan valid, Information readiness 18 dari 18 pernyataan dinyatakan valid, TIK readiness 20 dari 20 pernyataan dinyatakan valid, dan External Environment 8 dari 8 pernyataan dinyatakan valid. Sedangkan untuk wisatawan berjumlah 16 pernyataan yang semuanya dinyatakan valid.

Setelah dilakukan uji validitas, maka selanjutnya dilakukan uji reliabilitas menggunakan alpha cronbach pada tiap-tiap subdomain. Jumlah rata-rata Koefisien Cronbach Alpha $(\alpha)$ diperoleh dari survey di OPD adalah 0.88 , sedangkan untuk survey terhadap wisatawan adalah 0,87 . Karena hasil koefisien Alpha Cronbach $(\alpha)$ lebih besar dari 0,6 maka jawaban atas kuesioner penelitian mempunyai validitas tinggi dan apabila digunakan dapat menghasilkan pengukuran yang tepat.

\subsection{Hasil Survey OPD}

Berdasarkan hasil survey dan hasil analisis data di OPD Kominfo Kota Malang dapat diketahui hasil penilaian kesiapan untuk masing-masing komponen di OPD Pemerintah Kota Malang adalah sebagai berikut:

\subsubsection{Enterprise readiness}

Enterprise readiness segments adalah segmen yang digunakan untuk menilai kesiapan dari sisi organisasi yang kaitannya dengan strategi, manajemen dan pengelolaan sistem informasi.

Tabel 2. Hasil Penilaian Enterprise Readiness

\begin{tabular}{|l|l|l|}
\hline No & \multicolumn{1}{|c|}{ ENTERPRISE READINESS SEGMENT } & Hasil \\
\hline A1 & Strategi implemantasi teknologi & 4.23 \\
\hline A2 & Infrastruktur TIK berstandar Internasional & 3.48 \\
\hline A3 & Tersedianya staf bagian manajemen informasi & 4.15 \\
\hline A4 & Peran Bagian manajemen informasi & 4.45 \\
\hline A5 & Tugas dan fungsi Bagian manajemen informasi & 3.90 \\
\hline A6 & Ketersediaan Kebijakan/ strategi TIK & 4.03 \\
\hline A7 & Kebijakan/ strategi Informasi & 3.93 \\
\hline A8 & Tersedianya Sistem keamanan Informasi & 4.15 \\
\hline A9 & Perbaikan perangkat TIK jika terjadi kerusakan & 4.23 \\
\hline A10 & Pelatihan dan pendidikan peningkatan SDM & 4.65 \\
\hline A11 & Anggaran pengembangan teknologi informasi & 3.98 \\
\hline A12 & Tersedianya layanan publik secara elektronik & 4.15 \\
\hline A13 & Promosi TIK dalam pelayanan publik & 4.23 \\
\hline A14 & Inisiasi Kepala unit pelayanan informasi menggunakan TIK untuk pelayanan publik & 4.15 \\
\hline A15 & Kepala Unit memiliki Pendidikan dan pengalaman dibidang TIK & 3.85 \\
\hline A16 & Tersedianya prosedur/ mekanisme dalam analisis, desain dan implementasi sistem informasi & 3.93 \\
\hline A17 & Kesiapan OPD dalam membangun sistem e-government & 4.13 \\
\hline Rata & Rata Enterprise Readiness Segment & 4.11 \\
\hline
\end{tabular}

Berdasarkan penilaian Enterprise Readiness Segment diketahui tiga peringkat tertinggi yaitu Pelatihan dan pendidikan peningkatan SDM (A10), Peran Bagian manajemen informasi (A4), Inisiasi Kepala unit pelayanan informasi menggunakan TIK untuk pelayanan publik (A14). Sedangkan segmen dengan nilai terendah adalah : Tugas dan fungsi Bagian manajemen informasi (A5), Tersedianya prosedur/ mekanisme dalam analisis, desain dan implementasi sistem informasi (A16), Infrastruktur TIK berstandar Internasional (A2). 


\subsection{Human resources readiness}

Hasil penelitian kesiapan human resources readiness segment menunjukkan nilai 4.02 yang berarti di OPD Kominfo siap untuk menggunakan TIK dalam pelayanan informasi.

Tabel 3. Hasil Penilaian Human resources readiness

\begin{tabular}{|l|l|l|}
\hline No & \multicolumn{1}{|c|}{ Human Resources Segment } & Hasil \\
\hline B1 & Staf mampu menyediakan informasi yang dibutuhkan & 4.03 \\
\hline B2 & Staf memahami dasar hukum dan persyaratan dalam menyampaikan informasi & 3.98 \\
\hline B3 & Staf mampu mengevaluasi informasi dari sumber yang up to date dan akurat & 4.00 \\
\hline B4 & Staf mampu mengolah, dan menyiapkan informasi terkait penyelenggaraan pelayanan informasi & 4.00 \\
\hline B5 & Staf mampu menyimpan dan merawat dokumen informasi & 5.05 \\
\hline B6 & Staf mampu menganalisis, mengakses, dan menggunakan data dan informasi & 3.95 \\
\hline B7 & staf mampu mendapatkan data dan informasi yang dibutuhkan & 3.98 \\
\hline B8 & Staf mengerti manfaat dari informasi yang teratur dan terkelola dengan baik & 3.98 \\
\hline B9 & Staf berkemampuan cepat dalam mencari dan mendapatkan informasi yang dibutuhkannya & 3.85 \\
\hline B10 & Staf sadar akan pentingnya TIK dalam mendukung kegiatan pelayanan informasi publik & 4.30 \\
\hline B11 & OPD memiliki staf dengan Pendidikan dan keahlian bidang TIK & 3.98 \\
\hline B12 & Staf teknis profesional TIK di unit pelayanan informasi sudah sesuai kualifikasi & 3.83 \\
\hline B13 & Staf mampu dalam mengelola informasi dengan baik & 4.00 \\
\hline B14 & Staf profesional terampil di institusi jumlahnya sudah memadai & 3.20 \\
\hline B15 & Staf senior di OPD ikut dalam pelatihan TIK yang diadakan Pemerintah Kota Malang & 3.93 \\
\hline B16 & Tenaga teknis profesional dan berperan penting untuk mendukung pelayanan informasi & 4.23 \\
\hline B17 & Tersedianya technical support & 4.13 \\
\hline B18 & Staf mempunyai sikap positif dalam menggunakan TIK & 4.10 \\
\hline B19 & Bagian informasi mempunya tugas dan tanggung jawab khusus & 3.93 \\
\hline Rata Rata Human Resources Segment & $\mathbf{4 . 0 2}$ \\
\hline
\end{tabular}

Berdasarkan penilaian Human Resources Readiness Segment diketahui tiga peringkat tertinggi yaitu Staf mampu menyimpan dan merawat dokumen informasi (B5), Staf sadar akan pentingnya TIK dalam mendukung kegiatan pelayanan informasi publik (B10), Tenaga teknis profesional dan berperan penting, dibutuhkan untuk mendukung pelayanan informasi (B16). Sedangkan segmen dengan nilai terendah adalah : Staf berkemampuan cepat dalam mencari dan mendapatkan informasi yang dibutuhkannya (B9), Staf teknis profesional TIK di unit pelayanan informasi sudah sesuai kualifikasi (B12), Staf profesional terampil di institusi jumlahnya sudah memadai (B14).

\subsection{Information readiness}

Hasil penelitian kesiapan Information readiness segment menunjukkan nilai 4.12 yang berarti di OPD Kominfo siap mendukung pelayanan informasi.

Tabel 4. Hasil Penilaian Information readiness segment

\begin{tabular}{|l|l|l|}
\hline No & \multicolumn{1}{|c|}{ Information readinessSegment } & Hasil \\
\hline C1. & \multicolumn{1}{|c|}{ Tersediaannya ketentuan/ peraturan akses ke berbagai sumber informasi } & 3.98 \\
\hline C2. & $\begin{array}{l}\text { Tersedianya sarana elektronik yang disediakan untuk pengguna layanan dalam mengakses } \\
\text { informasi }\end{array}$ & 4.13 \\
\hline C3. & Informasi yang disediakan mudah untuk diakses & 4.20 \\
\hline C4 & Tersedianya mekanisme untuk mengumpulkan, menyimpan dan mencari informasi & 4.15 \\
\hline C5 & Ketersediaan tools/perangkat untuk menyimpan dan mendapatkan data/ informasi & 4.13 \\
\hline C6 & Format standar untuk penyimpanan/ pendokumentasian informasi organisasi sudah tersedia & 3.95 \\
\hline C7 & Ketersedianya tool untuk pencarian informasi & 4.05 \\
\hline C8 & Tersedianya website OPD & 4.50 \\
\hline
\end{tabular}




\begin{tabular}{|l|l|l|}
\hline No & \multicolumn{1}{|c|}{ Information readinessSegment } & Hasil \\
\hline C9 & Informasi yang disediakan di website OPD selalu update & 4.08 \\
\hline C10 & Informasi yang disediakan di website OPD beragam & 3.95 \\
\hline C11 & Proses update informasi website OPD dapat mudah dilakukan & 4.18 \\
\hline C12 & Website OPD digunakan untuk promosi & 4.00 \\
\hline C13 & Tersedianya sarana berbagi informasi di dalam dan di luar institusi & 4.15 \\
\hline C14 & $\begin{array}{l}\text { Tersedianya pedoman pengelolaan arsip dan dokumentasi secara elektronik di unit pelayanan } \\
\text { informasi }\end{array}$ & 4.08 \\
\hline C15 & Petugas teknis profesional di unit pelayanan informasi sesuai dengan kualifikasinya & 3.85 \\
\hline C16 & Bagian/ seksi informasi dapat terintegrasi dengan bagian yang lain & 3.90 \\
\hline C17 & Dalam mengakses informasi antar bagian di OPD tidak ada hambatan teknis & 4.68 \\
\hline C18 & TIK digunakan dalam kegiatan pelayanan informasi & 4.15 \\
\hline Rata Rata Information readiness Segment & $\mathbf{4 . 1 2}$ \\
\hline
\end{tabular}

Berdasarkan penilaian Information readiness Segment diketahui tiga peringkat tertinggi yaitu Dalam mengakses informasi antar bagian di OPD tidak ada hambatan teknis (C17), Tersedianya website OPD (C8), Informasi yang disediakan mudah untuk diakses (C3). Sedangkan segmen dengan nilai terendah adalah : Petugas teknis profesional di unit pelayanan informasi sesuai dengan kualifikasinya (C15), Bagian/ seksi informasi dapat terintegrasi dengan bagian yang lain (C16), Format standar untuk penyimpanan/ pendokumentasian informasi organisasi sudah tersedia (C6).

\subsection{TIK readiness}

Hasil penilaian kesiapan ICT readiness segment menunjukkan bahwa rata-rata komponen adalah 4,12 yang berarti bahwa OPD telah menyediakan TIK dengan baik dan siap untuk mendukung terselenggaranya unit pelayanan informasi.

Tabel 5. Hasil Penilaian TIK Readiness Segment

\begin{tabular}{|l|l|l|}
\hline No & \multicolumn{1}{|c|}{ TIK Readiness Segment } & Hasil \\
\hline D1. & $\begin{array}{l}\text { TIK dimanfaatkan di semua bagian/ unit kerja yang terkait dengan kegiatan pelayanan publik di } \\
\text { unit pelayanan informasi }\end{array}$ & 4.13 \\
\hline D2. & Staf mendapatkan fasilitas laptop/ personal komputer & 4.03 \\
\hline D3. & Koneksi internet sudah sesuai dengan kebutuhan & 3.93 \\
\hline D4 & Staf bisa mengakses internet yang tersedia & 4.23 \\
\hline D5 & OPD menyediakan internet untuk umum (Free WiFi) & 4.13 \\
\hline D6 & Koneksi ke layanan internet untuk umum (Free WiFi) dapat dilakukan dengan mudah & 4.10 \\
\hline D7 & Tersedianya bandwidth besar untuk akses ke jaringan & 4.03 \\
\hline D8 & Kualitas koneksitas jaringan sudah baik & 3.85 \\
\hline D9 & Website institusi dapat diakses dengan mudah & 4.23 \\
\hline D10 & Tersedianya Local Area Network (LAN) & 4.25 \\
\hline D11 & LAN digunakan di bagian/ unit kerja & 4.25 \\
\hline D12 & Perangkat TIK yang digunakan jenisnya beragam & 4.05 \\
\hline D13 & Akses internet dapat menjangkau pengguna di OPD & 4.23 \\
\hline D14 & OPD mendukung perkembangan TIK & 4.20 \\
\hline D15 & Saluran komunikasi yang tersedia jenisnya beragam & 3.98 \\
\hline D16 & Tersedianya layanan transaksi secara online di unit pelayanan informasi & 4.18 \\
\hline D17 & Layanan transaksi secara online di unit pelayanan informasi dapat diakses dengan mudah & 4.03 \\
\hline D18 & Ketersediaan broadband & 3.93 \\
\hline D19 & Jaringan yang tersedia dapat diakses dengan mudah & 4.23 \\
\hline D20 & Tingkat keamanan saat berinternet sudah baik & 4.00 \\
\hline Rata & Rata TIK Readiness Segment & $\mathbf{4 . 1 0}$ \\
\hline
\end{tabular}


Berdasarkan penilaian Information readiness Segment diketahui tiga peringkat tertinggi yaitu LAN digunakan di bagian/ unit kerja (D11), Tersedianya Local Area Network (LAN) (D10), Jaringan yang tersedia dapat diakses dengan mudah (D19). Sedangkan segmen dengan nilai terendah adalah: Kualitas koneksitas jaringan sudah baik (D8), Koneksi internet sudah sesuai dengan kebutuhan (D3), Ketersediaan broadband (D18).

\subsection{External Environment}

Hasil penilaian kesiapan external environment readiness segment menunjukkan bahwa ratarata komponen penilaian pada skala 4,04. Nilai tersebut menunjukan bahwa lingkungan eksternal siap mendukung penggunaan TIK dalam pembentukan unit pelayanan informasi.

Tabel 5. Hasil Penilaian Human Resources Segment

\begin{tabular}{|c|c|c|}
\hline No & Human Resources Segment & Hasil \\
\hline E1. & Kualitas layanan telekomunikasi termasuk bandwidth sudah memadai & 3.80 \\
\hline E2. & TIK dapat dijangkau oleh service provider & 3.98 \\
\hline E3. & Tersedianya peraturan/ dasar hukum dan persyaratan di unit pelayanan informasi & 4.00 \\
\hline E4 & Jaringan listrik di institusi cukup dan dapat diandalkan & 4.15 \\
\hline E5 & Pemerintah mendukung Kesiapan Elektronik & 4.23 \\
\hline E6 & Tersedianya sarana TIK yang dapat digunakan secara bersama-sama & 4.08 \\
\hline E7 & Tersedianya kebijakan informasi nasional lain yang mendukung unit pelayanan informasi & 4.13 \\
\hline E8 & Perlindungan terhadap konsumen diatur dalam regulasi & 3.95 \\
\hline \multicolumn{2}{|c|}{ Rata Rata Information readiness Segment } & 4.04 \\
\hline
\end{tabular}

Berdasarkan penilaian External Environment readiness Segment diketahui tiga peringkat tertinggi yaitu Pemerintah mendukung Kesiapan Elektronik (E5), Jaringan listrik di institusi cukup dan dapat diandalkan (E4), Tersedianya kebijakan informasi nasional lain yang mendukung unit pelayanan informasi (E7). Sedangkan segmen dengan nilai terendah adalah : Kualitas layanan telekomunikasi termasuk bandwidth sudah memadai (E1), Perlindungan terhadap konsumen diatur dalam regulasi (E8), TIK dapat dijangkau oleh service provider (E2).

\section{KESIMPULAN}

Nilai dimensi Enterprise readiness yaitu 4.11, human resources readiness yaitu 4.02, Information readiness yaitu 4.12, TIK readiness yaitu 4.10, dan External Environment yaitu 4.04. Berdasarkan lima dimensi kesiapan hasil yang didapat dan pengolahan data survey di OPD Komunikasi dan Informatika dapat dinilai bahwa kesiapan OPD dalam menyediakan layanan informasi berada pada skala 4.07 yang berarti kesiapan pariwisata cerdas di Kota Malang dinyatakan siap.

\section{DAFTAR PUSTAKA}

[1] A Ghavamifar, A., Beig, L., \& Montazer, G. The comparison of different e-readiness assessment tools, ICT: From Theory to Applications. ICTTA . 2008.

[2] Mohitmafi, K., Hanafizadeh, P. A Selection Framework of E-Business Model by Assessing Organizational E-Readiness. IEEE International Conference on Industrial Engineering and Engineering Management (IEEM). 2016.

[3] Pradhan, M.K., Oh, J., Lee.H. Understanding Travelers' Behavior for Sustainable Smart Tourism: A Technology Readiness Perspective. 2018. 
[4] Springer Buhalis, D., \& Law, R. Progress in information technology and tourism management: 20 years on and 10 years after the Internet. The state of eTourism research. Tourism management, 29(4), 609-623. 2008.

[5] Buhalis, D. Marketing the competitive destination of the future. Tourism management, 21(1), 97-116. 2000.

[6] APEC readiness initiative 2000. Ecommerce Readiness Assessment Guide. 2000. Diakses pada 2 Mei 2016. http://publications.apec.org/publication-detail.php?pub_id=647.

[7] Mutula, Stephen M; Brakel, Pieter V. An Evaluation of E -Readiness Assessment Tools With Respect to Information Access: Towards and Integration Information Rich Tool. International journal of Information Management, Volume 26, 212-223. Botswana: University of Botswana; South of Africa: Cape Peninsula University of Technology. 2006.

[8] Hourali, M., M. Fathian, and A. Montazeri. A Model for E-readiness Assessment of Iranian Small and Medium Enterprise. Jornal of Faculty of Engineering 41. 2008.

[9] Bădiţă, A. Approaches to The Analysis and Evaluation of Urban Tourism System Within Urban Destinations. Revista de turism-studii si cercetari in turism, (16), 58-66. 2013.

[10] Đurek, V., Ređep, NB., Review on e-readiness assessment tools. Central European Conference on Information and Intelligent Systems. 2016.

[11] Keoduangsine, S., Goodwin, R. Measuring E-Readiness Assessment: The case of Laotian Organisations. The 6th International Conference on Information Technology and Applications (ICITA ), ISBN: 978-981-08-3029-8. 2009.

[12] Bădiţă, A. Approaches to The Analysis and Evaluation of Urban Tourism System Within Urban Destinations. Revista de turism-studii si cercetari in turism, (16), 58-66. 2013.

[13] Readiness for the Networked World. A Guide for Developing Countries. 2000. http://www.readinessguide.org/.

[14] Ghavamifar, A., Beig, L., \& Montazer, G. The comparison of different e-readiness assessment tools, ICT: From Theory to Applications. ICTTA. 2008. 